\title{
Stakeholder discourses on urban mangrove conservation and management
}

\author{
Katherine Vande Velde ${ }^{a, c, *}$, Jean Hugée, $e^{a, c, d, e}$, Daniel A. Friess ${ }^{b}$, Nico Koedam ${ }^{c}$, \\ Farid Dahdouh-Guebas ${ }^{\mathrm{a}, \mathrm{c}}$ \\ ${ }^{\mathrm{a}}$ Laboratory of Systems Ecology and Resource Management, Département de Biologie des Organismes, Université Libre de Bruxelles - ULB, Av. F.D. Roosevelt 50, CPi 264/ \\ 1, 1050, Brussels, Belgium \\ ${ }^{\mathrm{b}}$ Department of Geography, National University of Singapore, 1 Arts Link, 117570, Singapore \\ ${ }^{\mathrm{c}}$ Ecology \& Biodiversity, Laboratory of Plant Biology and Nature Management, Biology Department, Vrije Universiteit Brussel - VUB, Pleinlaan 2, VUB-APNA-WE, 1050, \\ Brussels, Belgium \\ ${ }^{\mathrm{d}}$ Centre for Sustainable Development, Ghent University. Poel 16, 9000, Ghent, Belgium \\ ${ }^{\mathrm{e}}$ Centre for Environmental Science, University of Hasselt, Belgium
}

A R T I C L E I N F O

\section{Keywords:}

Stakeholder discourses

Inclusive conservation

Mangrove forest

Q methodology

Singapore

Urban biodiversity

\begin{abstract}
A B S T R A C T
In Southeast Asia, mangrove forest cover and biodiversity has shown a rapid decline in recent decades, despite extensive conservation efforts. Identifying and analysing discourses on biodiversity conservation improves our knowledge and understanding of stakeholder perspectives (including normative values and socially constructed viewpoints) on biodiversity conservation within a specific social-ecological context. Considering these perspectives in a decision-making context contributes to the long-term sustainability of resulting conservation approaches, thus contributing to continued biodiversity conservation efforts in the far future. We consider the urban City State of Singapore to identify and interpret stakeholder discourses -including values and socially constructed viewpoints-on (effective) mangrove biodiversity conservation and management in an urban context. Using the Q methodology, we: (i) delineate and describe mangrove conservation and management discourses in Singapore and (ii) extract consensual perspectives common to discourses as a basis for management recommendations. Areas of agreement and disagreement on motivation, prioritization and responsibilities related to mangrove conservation and management are described based on numerical (i.e. sorting of statements along an ordinal scale) and qualitative data (i.e. structured interviews). There was a large overlap between discourses, suggesting that disagreement between various stakeholders may not be a prominent inhibitor of future decision making regarding mangrove conservation and management. It seems stakeholders realise the urban context strongly limits the range of realistic conservation and management approaches of mangrove forests, resulting in the larger overlap between discourses. Generally, all participants agree no further loss of existing Singapore mangroves should be allowed. The most important recommendations to reach this ultimate objective include indefinite legal protection and increase of mangrove areas under national park and nature reserve status, as well as continued promotion of mangrove's cultural ecosystem services. The identified discourses can inform decision-making by deducing shared stakeholder objectives based on the consensus values and perspectives. These shared objectives can readily be incorporated in decision-making processes on mangrove conservation and management in an urban context.
\end{abstract}

\section{Introduction}

Biodiversity conservation is not value-free, with conservation and management decisions based on the complex interaction between values, evidence, interest and other context-depending factors (Levine et al., 2015). While decision-making should be based on the location's biophysical context and conservation evidence (the latter being based on failures and successes from past conservation case studies; Sutherland et al., 2004), the ultimate success of a conservation intervention also depends on the non-biophysical context. The latter includes local stakeholder and actor's normative values and socially constructed viewpoints on conservation and management, their expectations from conservation and management, and local institutional characteristics (Soulé, 1985; Brown, 2003; Chan et al., 2007).

\footnotetext{
* Corresponding author. , Laboratory of Systems Ecology and Resource Management, Département de Biologie des Organismes, Université Libre de Bruxelles - ULB, Av. F.D. Roosevelt 50, CPi 264/1, 1050, Brussels, Belgium.

E-mail address: kathvdev@ulb.ac.be (K. Vande Velde).
} 
Regarding non-biophysical social patterns and processes, research on the economic and political (i.e.: administration and policy making) systems and institutions externally influencing environmental problems have been relatively well researched. More so than research on normative values - defined by Crane (2010) as socially defined and held values and ideals regarding desirability or propriety of a circumstance or practice - and socially constructed viewpoints on biodiversity conservation and management (reflecting people's intentions and desires) (Stojanovic et al., 2016; Crane, 2010).

Addressing this knowledge gap is crucial, as local people's values and socially constructed viewpoints delimit and highlight the choices decision-makers can make (whether decision-making is initiated topdown or bottom-up) which are socially acceptable (Redman et al., 2004; Ostrom, 1999). Based on ethical principles and/or pragmatic considerations of the decision-makers, some may restrict themselves to these delimited options. Moreover, besides emergent properties such as resilience and complexity of the system, social acceptability should also be considered a fundamental parameter of long-term sustainability of the applied biodiversity conservation and management approach and the resulting system (Redman et al., 2004). Multiple studies have found that long-term effectiveness of conservation and/or management approaches depends on willingness of locals to comply with regulations and willingness to monitor one another (Ostrom, 2009). Both are unlikely to be obtained if proposed biodiversity conservation and management approaches are experienced as unacceptable by locals. Aligning with stakeholder's and actor's values and viewpoints thus indirectly leads to long-term sustainability, especially in areas where topdown enforcement is lacking or inconsistent.

It is important to consider perspectives on biodiversity conservation and management actions at relevant scales, especially in research with an applied orientation, linking results with applications in decisionmaking. The critical analysis of different values and viewpoints (i.e. perspectives) shaping conservation approaches at a global scale has often led to an over-simplified dichotomy, artificially dividing conservationists based upon opposite value systems defined by the authors (Tallis and Lubchenco, 2014; Kueffer and Kaiser-Bunbury, 2014; Holmes et al., 2017) (Table 1). These generalised perspectives have led to researchers debating which side of these 'scientist-defined' dichotomies is the 'right side', based both on advocating certain perspectives (values and socially constructed viewpoints) and on empirical evidence from failed and successful conservation case studies, without resulting in applicable conclusions (e.g. Soulé, 2013; Miller et al., 2014; Marvier, 2014) (Miller et al., 2011; Robinson, 2011; Petriello and Wallen, 2015).

To move beyond this conservation gridlock caused by a priori dismissal of conservation approaches at wider scale, this study is inspired by the concept of 'inclusive conservation'. We define inclusive conservation as a process of deliberation where all values, socially and empirically informed viewpoints on conservation and management approaches relevant to the local context are considered as valid to consider (Brown, 2003; Miller et al., 2011; Tallis and Lubchenco, 2014). Deliberation in a decision-making context then leads to the selection of one, or the integration of multiple conservation approaches and associated conservation values, through careful consideration and discussion (Brown, 2003). By narrowing the focus to one social-

Table 1

Dichotomic representations of conservation values and viewpoints with linked conservation approaches at an unspecified (theoretical) or global scale.

\begin{tabular}{ll}
\hline Dichotomic representation & Reference paper(s) \\
\hline $\begin{array}{l}\text { Biocentrism/Ecocentrism/Deep Ecology vs. } \\
\text { Anthropocentrism }\end{array}$ & Grey (1993) \\
& Gagnon Thompson and \\
Conservation/Parks vs. Poverty/People & Adams (1994) \\
Nature protectionist vs. Social conservationist & Miller et al. (2011) \\
Ecological justice vs. Social justice & Kopnina (2016) \\
\hline
\end{tabular}

ecological system (i.e. non-pristine mangrove forests, currently influenced by humans) and one context (i.e. urban), we facilitate reaching well-informed (including inputs on social acceptability) and applicable decisions on mangrove conservation and management.

Mangrove forests are a useful system to interrogate shared perspectives on mangrove conservation and management because they are a highly threatened ecosystem across much of the tropics, particularly in Southeast Asia (Hamilton and Casey, 2016; Thomas et al., 2017). They are a key ecosystem experiencing human-environment conflict, due to their position in the rapidly urbanizing coastal zone. With population densities in the coastal zone higher than the average (Neumann et al., 2015), urbanisation is an important local proximate driver of mangrove deforestation in Southeast Asia, particularly Vietnam, the Gulf of Thailand and in southern Malaysia/Singapore (Richards and Friess, 2016). This often means the direct loss of mangroves through land reclamation, and continuing mangrove degradation due to pollution and overutilization close to urban and peri-urban areas (Lai et al., 2015; Branoff, 2017; Nfotabong-Atheull et al., 2013).

The objective of this study is to increase our understanding of shared perspectives (including normative values and socially constructed viewpoints) on mangrove conservation and management, particularly in urban settings, using the example of the tropical urban nation of Singapore. This is especially important in urban areas, where human-environment interactions and conflicts are more likely to be high. The urban nation of Singapore is emblematic of urbanisation in the rest of Southeast Asia, and a logical development endpoint for many other rapidly urbanizing areas in the region. Singapore has lost more than $90 \%$ of its mangrove area since the 1800 s, and land use decisions between future development and the conservation of mangrove ecosystem services are ongoing (Yee et al., 2010; Richards and Friess, 2017).

We approach this objective by identifying stakeholder discourses on mangrove management and conservation in Singapore (including stakeholders with and without agency). In this research with an applied orientation towards improving (acceptability of) decision-making on mangrove conservation and management in an urban context, discourses can be broadly described as shared, structured ways of perceiving and valuing the world (Hajer, 1995; Dryzek, 2005). More specifically, shared frames of meaning, describing the used language (and the meanings/ideologies implied in those words) as well as uncovering the underlying shared normative values and socially constructed perspectives relevant to mangrove conservation and management in an urban context (Arts and Buizer, 2009).

Epistemologically based on the work of Foucault (1984), our research strategy includes an analytical emphasis on how discourses are linked to social practices, thus recognizing the ability of discourses to actively influence society by making certain actions acceptable and others unacceptable (Hajer, 1995, Arts and Buizer, 2009). E.g. how institutional characteristics and historical events act as forming factors for individual discourses; how certain discourses influence collective actions; how certain discourses are linked to collective inclination or opposition to certain actions.

We use the Q-methodology to identify stakeholder discourses (including shared values and viewpoints). In doing so, this study: (i) delineates and describes discourses on (effective) mangrove conservation and management held by a variety of stakeholders in Singapore and (ii) identifies areas of consensus (i.e. values and viewpoints shared by all discourses) as a base for management recommendations applicable to urban contexts in the form of objectives (i.e. directional actions).

\section{Material and methods}

\subsection{Study area}

Singapore, located on the equator to the south of Peninsular Malaysia is characterised by rapid post-independence urban 
development, a large extent of urban infrastructure (39\% of the current land surface) and an entirely urban human population (Yee et al., 2011, UN DESA, 2014). Nearly half of the green areas that do remain are actively managed, and the remainder are generally heavily modified or disturbed (Yee et al., 2011). Mangroves cover approximately $1 \%$ of Singapore's land surface $\left(6,4 \mathrm{~km}^{2}\right)$ and less than $10 \%$ of their original range of $75 \mathrm{~km}^{2}$ in 1899 (Yee et al., 2010; Lai et al., 2015; Corlett, 1992), with loss driven by reservoir construction and land reclamation (Lai et al., 2015). Despite the relatively small and fragmented extent in this urban landscape, Singapore's remaining mangroves continue to provide a range of important ecosystem services to the nation (Friess, 2017) and act as an important refuge for native and migratory biodiversity (Shufen et al., 2012). While mangrove rehabilitation efforts are ongoing to try and offset historic losses, a further 33\% of remaining national mangrove extent will be lost according to plans projecting land use over the next 2 decades (Lai et al., 2015).

\subsection{Discourse identification by way of $Q$ methodology}

The $\mathrm{Q}$ methodology (QM) is commonly applied to identify discourses, which allows us to identify shared values and perspectives. The QM has been increasingly applied to identify the complex values and perspectives linked to environmental challenges, such as biodiversity conservation and management (Zabala et al., 2018, Mukherjee et al. 2017). Alternatively, we could have used qualitative interviews. However, Q methodology can combine the benefits of both quantitative data and qualitative data. Individual stakeholders are presented with a range of statements that they rank along an ordinal scale, after which additional questions are asked in a 'post-sorting interview' to gather additional qualitative information relevant to the statements ranked. In a second stage, stakeholders are grouped based on the correlation between the individual rankings, using a multivariate data analysis approach. The sorting patterns of the grouped stakeholders guide the description of the discourses: sorting patterns of individual groups represent individual discourses based on their values and perspectives expressed through the respective statement rankings and qualitative post-sorting interviews (van Exel and de Graaf, 2005; Watts and Stenner, 2012). The qualitative post-sorting interview permits flexibility during the interview process as well as in depth understanding of participant values and viewpoints. On the other hand, the quantitative sorting of statements gives structure to both the interview process and the data analysis, strengthening the findings (Mukherjee et al. 2017).

\subsubsection{Selection of participants - stakeholder analysis}

We intentionally selected a broad range of stakeholders who have a certain interest - ranging from mild to strong - in mangrove conservation and/or management (Table 2). This selection was based on local networks, an online search for authors of context-relevant peerreviewed literature and a mapping of stakeholders through online profiles, complemented with a snowball sampling approach (i.e. the identification of stakeholders by other participants; Reed et al., 2009). The final set of participants who completed the sorting and post-sorting interview (the 'P-set') included 37 participants $(\mathrm{P})$ with different professional and social backgrounds, resulting in a range of knowledge and interest levels on mangroves (Table 2). Main (professional) activities of participants included research focussing on mangroves (14\%) as well as other topics $(22 \%)$, NGO (14\%), corporate sector/consultancy $(27 \%)$, tourist sector (5\%), education sector (3\%), student $(8 \%)$ and government officials (8\%). The P-set had a male/female ratio of 2,08 . Within the P-set $32 \%$ was $20-40$ years old, $63 \%$ was $40-60$ years old, $5 \%$ was older than 60 . By targeting varied professional backgrounds, we aspired to cover the fullest spectrum of discourses to understand the broadest values and perspectives regarding (effective) mangrove conservation and management in Singapore (Dryzek and Niemeyer, 2008).
Table 2

List of participants (P), associated discourse (D) on which the Ps are significantly loading ( $\mathrm{p}<0,001$; threshold value significant loading $=0,47$ ) and $P$ characterisation in terms of personal interest and knowledge level (based on stakeholder analysis and post-sorting interviews). Grey shading indicates excluded $\mathrm{P}$ which will not be included for the calculation of z-scores, i.e. when the $P$ had relatively low commonalities on the first 4 factors and loaded significantly on separate factors above 4 when we intentionally extracted more factors than we expected to keep.

\begin{tabular}{|c|c|c|c|}
\hline $\mathrm{D}$ & $\mathrm{P}$ & Characterisation & \\
\hline 1 & 1 & Mangrove & Expert \\
\hline 1 & 3 & Mangrove & Expert \\
\hline 1 & 5 & Mangrove & Expert \\
\hline 1 & 7 & Mangrove & Engaged \\
\hline 1 & 10 & Mangrove & Engaged \\
\hline 1 & 12 & Mangrove & Engaged \\
\hline 1 & 16 & Mangrove & Engaged \\
\hline 1 & 30 & Mangrove & Engaged \\
\hline 1 & 33 & Mangrove & Engaged \\
\hline 1 & 34 & Mangrove & Engaged \\
\hline 1 & 39 & Other & Expert \\
\hline 1 & 40 & Mangrove & Engaged \\
\hline 1,2 & 36 & Mangrove & Expert \\
\hline 2 & 2 & Other & Expert \\
\hline 2 & 8 & Other & Expert \\
\hline 2 & 9 & Other & Engaged \\
\hline 2 & 14 & Mangrove & Engaged \\
\hline 2 & 15 & Other & Expert \\
\hline 2 & 18 & Other & Engaged \\
\hline 2 & 19 & Other & Engaged \\
\hline 2 & 26 & Other & Engaged \\
\hline 2 & 29 & Other & Expert \\
\hline 2 & 31 & Other & Engaged \\
\hline 2 & 38 & Mangrove & Engaged \\
\hline 2,3 & 20 & Other & Engaged \\
\hline 3 & 13 & Mangrove & Engaged \\
\hline 3 & 24 & Other & Engaged \\
\hline 3 & 28 & Other & Expert \\
\hline 4 & 32 & Mangrove & Engaged \\
\hline / & 6 & Mangrove & Engaged \\
\hline I & 17 & Mangrove & Expert \\
\hline / & 23 & Other & Expert \\
\hline / & 25 & Mangrove & Engaged \\
\hline 4 & 4 & Mangrove & Expert \\
\hline 4 & 21 & Other & Engaged \\
\hline 4 & 27 & Mangrove & Engaged \\
\hline 4 & 37 & Other & Engaged \\
\hline
\end{tabular}

\subsubsection{Selection and sorting of discourse statements}

Data collection took place from February to March 2016. The quantitative step in the QM consists of participants expressing their level of agreement or disagreement with statements relevant to the topic at hand, by sorting them along an ordinal scale. We allowed participants to rank the statements using a free distribution (i.e. there is no pre-determined number of statements to sort under each category) and presented statements in a randomized order on individual cards they could physically sort during face to face interviews. There were 9 ordinal categories, ranging from - 4 (most disagree) over 0 (no opinion/ equally agree and disagree/topic is too sensitive to rank) to +4 (most agree) (van Exel and de Graaf, 2005).

In total, we presented 50 textual statements - forming the 'Q-set' - to rank by the participants. These were formulated based on a literature search of peer-reviewed literature through the databases Scopus, Research Gate and Web of Knowledge (search operators: (Conservation OR Biodiversity) AND (Mangrove* OR Estuar* OR Wetland*) AND (Singapore* OR "South-East Asia" OR "South East Asia" OR "Malay Peninsula") (AND Urban*)) (last accessed on 31/01/2016). Through this review, 52 articles relevant to socio-ecological and socio-economic aspects of biodiversity conservation and management within Southeast Asian urban contexts were selected. Value-statements and perspectives relevant to mangrove forest conservation and management were 
Table 3

Statements and statistics: z-scores (z-sc), ranks (r) (cf. Table 4) and 'grouping'. Discourses are represented by their respective numbers: 1, $2 \& 3$ in 'grouping', whereby brackets separate significantly differing z-sc pertaining to the respective discourse(s). Grey shading indicates statements with no significant difference between z-sc of the respective discourses.

\begin{tabular}{|c|c|c|c|c|c|c|c|c|}
\hline \multicolumn{2}{|c|}{ Statement (S) } & \multirow[t]{2}{*}{ Grouping } & \multicolumn{2}{|l|}{ D1 } & \multicolumn{2}{|l|}{ D2 } & \multicolumn{2}{|l|}{ D3 } \\
\hline & & & z-sc & $\mathrm{r}$ & z-sc & $\mathrm{r}$ & z-sc & $\mathrm{r}$ \\
\hline 1 & Mangrove areas in parks and nature reserves are adequately managed for educational purposes & $(1,3)(2)$ & 0.246 & 1 & -0.246 & 0 & 0.611 & 2 \\
\hline 2 & $\begin{array}{l}\text { The government should develop a general plan to regulate and enforce the conservation of all remaining } \\
\text { mangroves }\end{array}$ & & 0.997 & 4 & 1.252 & 4 & 0.926 & 3 \\
\hline 3 & $\begin{array}{l}\text { The number of mangrove areas with some legal protection from development have decreased over the last few } \\
\text { decades }\end{array}$ & $(1,3)(2)$ & -1.378 & -2 & 0.886 & 3 & -1.279 & -2 \\
\hline 4 & Conservation of natural mangrove areas is sufficiently integrated by coastal developers & & -1.281 & -2 & -0.948 & -2 & -1.201 & -2 \\
\hline 5 & Specific locations where wildlife needs are paramount, should not be used for recreation or eco-tourism & $(2,3)(1)$ & 0.045 & 0 & 0.477 & 2 & 0.715 & 3 \\
\hline 6 & Mangrove areas and its fauna and flora should be protected because of their inherent value & & 1.136 & 4 & 1.075 & 4 & 0.743 & 3 \\
\hline 7 & Mangrove areas with no legal protection should be converted to industry or housing & & -2.155 & -4 & -2.024 & -4 & -2.207 & -4 \\
\hline 8 & Mangrove areas should be protected because Singapore is an example to developing states in South-East Asia & $(1,3)(2)$ & 0.968 & 3 & -0.149 & 0 & 0.495 & 2 \\
\hline 9 & Government initiated campaigns play a crucial role in shaping citizens' views on biodiversity considerations & & 0.328 & 1 & 0.588 & 2 & 0.574 & 2 \\
\hline 10 & Mangrove areas should be protected when they are ecologically valuable to birds & (1) (2) & 0.594 & 2 & 1.131 & 4 & 0.954 & 3 \\
\hline 11 & Mangroves are safe and should be visited by children for educational or recreational purposes & & 0.014 & 0 & 0.310 & 1 & 0.409 & 1 \\
\hline 12 & Conservation of natural mangrove areas is sufficiently integrated by coastal authorities & $(1,3)(2)$ & -0.764 & -1 & -1.522 & -3 & -0.631 & -1 \\
\hline 13 & Mangrove areas should be protected when they contain threatened species & & 0.858 & 3 & 1.224 & 4 & 0.812 & 3 \\
\hline 14 & Non-Governmental organizations (NGOs) play a big role in preserving, protecting \& reforesting mangroves areas & $(1,2)(3)$ & 1.018 & 4 & 0.683 & 2 & 0.006 & 0 \\
\hline 15 & Citizens should be involved in the maintenance and monitoring of mangrove areas & $(2,3)(1)$ & 0.804 & 3 & 0.043 & 0 & 0.079 & $\mathbf{0}$ \\
\hline 16 & Human-nature encounters are necessary to increase peoples' connection with nature & $(1,2)(3)$ & 1.048 & 4 & 1.013 & 4 & 0.373 & 1 \\
\hline 17 & $\begin{array}{l}\text { Excluding biodiversity considerations from coastal development projects will lead to social and environmental } \\
\text { issues, ultimately causing economic losses }\end{array}$ & $(1,2)(3)$ & -0.032 & 0 & 0.047 & 0 & 0.692 & 2 \\
\hline 18 & $\begin{array}{l}\text { Expected economic growth from urban development justifies abolishing the legal protection (degazetting) and } \\
\text { development of previously protected mangroves }\end{array}$ & (1) (3) & -1.739 & -3 & -1.904 & -3 & -2.432 & -4 \\
\hline 19 & The scientific value of mangrove areas in Singapore is of great importance & & 0.882 & 3 & 0.658 & 2 & 0.481 & 2 \\
\hline 20 & Mangroves are ideal as dumping grounds for urban waste material & & -2.267 & -4 & -2.255 & -4 & -2.537 & -4 \\
\hline 21 & Traditional local media outlets play a crucial role in shaping citizens' views on biodiversity considerations & (1) (3) & 0.725 & 3 & 0.605 & 2 & 0.128 & 0 \\
\hline 22 & Mangrove areas in parks and nature reserves are adequately managed for recreational and cultural purposes & (2) (3) & 0.029 & 0 & -0.344 & -1 & 0.459 & 2 \\
\hline 23 & The current mangrove area is too limited to provide adequate climate resilience & $(2,3)(1)$ & -0.230 & 0 & 0.331 & 1 & 0.346 & 1 \\
\hline 24 & The protection of the environment has always been a priority for the government & $(2,3)(1)$ & -0.629 & -1 & -1.206 & -2 & -1.362 & -2 \\
\hline 25 & Climate change and the resulting sea level rise will affect all mangroves despite conservation actions & $(2,3)(1)$ & -0.237 & 0 & 0.527 & 2 & 0.469 & 2 \\
\hline 26 & Classes about environmental concerns and nature should be taught more at secondary school levels & & 0.812 & 3 & 0.672 & 2 & 0.587 & 2 \\
\hline 27 & Mangrove areas and its fauna and flora should be protected because of their use to humans & & 0.287 & 1 & -0.050 & 0 & 0.042 & 0 \\
\hline 28 & Mangrove areas are part of Singapore's cultural heritage & (1) (2) & 1.014 & 4 & 0.551 & 2 & 0.601 & 2 \\
\hline 29 & Eco-tourism should be encouraged to compensate for the management costs of natural mangrove areas & & -0.064 & 0 & -0.130 & 0 & 0.016 & 0 \\
\hline 30 & The quality of Singapore's green areas increases for visitors through incorporation of native mangrove strips & (1) (2) & 0.935 & 3 & 0.527 & 2 & 0.848 & 3 \\
\hline 31 & Mangrove areas should be protected when they are ecologically valuable & $(1,2)(3)$ & 0.887 & 3 & 1.096 & 4 & -0.025 & 0 \\
\hline 32 & $\begin{array}{l}\text { Public park management and nature reserve (national park, natural area) management cannot both prioritize } \\
\text { biodiversity conservation and recreation }\end{array}$ & & -1.075 & -2 & -1.045 & -2 & -0.624 & -1 \\
\hline 33 & $\begin{array}{l}\text { Adapting coastal infrastructures to incorporate biodiversity can compensate for the inevitable loss of Singapore's } \\
\text { mangroves in the future }\end{array}$ & $(1,2)(3)$ & -0.541 & -1 & -0.414 & -1 & 0.917 & 3 \\
\hline 34 & $\begin{array}{l}\text { A top-down approach is necessary to insure coordination among the various agencies involved in coastal } \\
\text { planning }\end{array}$ & & -0.023 & 0 & 0.328 & 1 & 0.327 & 1 \\
\hline 35 & Mangrove areas are recognised by the government (urban decision makers) for their carbon storage potential & (1) (2) & -0.751 & -1 & -1.101 & -2 & -0.824 & -1 \\
\hline 36 & Presence of mangroves are not required because the urban environment satisfies all human needs & (1) (2) & -2.229 & -4 & -1.766 & -3 & -2.207 & -4 \\
\hline 37 & Disturbance to sensitive mangrove areas, from educational \& recreational activities, should be minimized & & 0.946 & 3 & 0.792 & 3 & 0.515 & 2 \\
\hline 38 & $\begin{array}{l}\text { Native biodiversity considerations should be a management priority in all of Singapore's green areas (natural } \\
\text { and constructed) }\end{array}$ & & 0.977 & 3 & 0.722 & 3 & 0.954 & 3 \\
\hline 39 & Singapore lacks the space to allow the preservation of all remaining mangrove areas & & -1.415 & -3 & -1.213 & -2 & -1.024 & -2 \\
\hline 40 & The approach to mangrove conservation should be consultative (involving many stakeholders) & & 0.705 & 3 & 0.749 & 3 & 0.620 & 2 \\
\hline 41 & $\begin{array}{l}\text { Financial support is necessary to generate new data to allow better informed decisions in case of conflicts } \\
\text { between mangroves and coastal development projects }\end{array}$ & & 0.742 & 3 & 0.607 & 2 & 0.858 & 3 \\
\hline 42 & $\begin{array}{l}\text { Pollution of mangrove areas should be addressed by government agencies to allow safe consumption of shellfish } \\
\text { or fish from mangroves }\end{array}$ & & 0.735 & 3 & 0.809 & 3 & 0.564 & 2 \\
\hline 43 & The best way to allow effective protection of the environment is to become richer (at the state level) & (1) (2) & -0.759 & -1 & -1.420 & -3 & -1.276 & -2 \\
\hline 44 & Mangrove areas in parks and nature reserves are adequately managed for biodiversity conservation purposes & (1) (2) (3) & -0.310 & -1 & -0.990 & -2 & 0.267 & 1 \\
\hline 45 & Only the largest mangrove areas should be protected, because smaller patches are not valuable & $(1,3)(2)$ & -2.185 & -4 & -1.394 & -2 & -1.959 & -3 \\
\hline 46 & $\begin{array}{l}\text { Including biodiversity considerations in coastal development projects (Corporate Social Responsibility) is an } \\
\text { important marketing tool, leading to substantial commercial benefits }\end{array}$ & $(1,2)(3)$ & -0.021 & 0 & -0.068 & 0 & 0.743 & 3 \\
\hline 47 & The army should play an active role in conservation of mangrove areas & $(1,3)(2)$ & 0.133 & 0 & -0.873 & -2 & -0.086 & 0 \\
\hline 48 & Mangrove areas should be protected when they contain species unique to Singapore & (2) (3) & 0.880 & 3 & 1.166 & 4 & 0.528 & 2 \\
\hline 49 & $\begin{array}{l}\text { Citizens should be given more responsibility and account for their own actions related to conservation of the } \\
\text { environment }\end{array}$ & & 0.622 & 2 & 0.935 & 3 & 0.848 & 3 \\
\hline 50 & Environmental Impact Assessments (EIA) should be more transparent towards the public & $(2,3)(1)$ & 0.719 & 3 & 1.261 & 4 & 1.165 & 4 \\
\hline
\end{tabular}

gathered and subsequently sorted, with statements sharing a similar value or perspective merged into one overarching statement included in the final Q-set (Watts and Stenner, 2012). The Q-set was tested with the help of 4 preparatory interviews with mangrove and QM researchers, and 2 pilot sorts (including post-sorting interviews). This resulted in slight alterations and a final Q-set of 50 statements (Table 3). The postsorting interview contained 25 overarching questions, reflecting on the 50 statements previously sorted. This complementary qualitative interview covered the themes also present in the statements, including motivation to conserve mangroves, prioritization of different land-uses 
and different mangrove areas, and responsibility of stakeholders and actors involved in mangrove conservation and management in Singapore.

\subsubsection{Numerical data analysis}

Data analysis was conducted using the $\mathrm{R}$ package 'qmethod' (Zabala, 2014) within the open source software R 3.3.1 ${ }^{\complement}$. Participants (explanatory/fixed variables) were grouped based on a matrix of association between the sorts (dependent variables) through Principal Component Analysis (PCA). By grouping participants with similar sorts and thus similar values, the number of discourses was reduced. First, we determined the number of factors to extract and rotate. Then participant loadings were calculated, indicating how representative the individual rotated factors are for the individual participants (ranging from -1 when participants were negatively correlated to the factor to +1 when participants were positively correlated to the factor). Participants who had significant loadings on the same rotated factor were grouped (i.e. the loading the participants on the respective factor is significantly different from 0 ). These groups of 'likeminded' participants, were then used to describe the respective discourses they support. The description of the discourses was based on the individual statements' z-scores per factor (i.e. the weighted averages of the scores given to the individual statements by the grouped participants ${ }^{1}$ ) in combination with the post-sorting interviews (Zabala, 2014; Watts and Stenner, 2012).

Within PCA, there are several methodological options to choose from when determining the type of matrix of association, the number of factors to extract and the type of rotation of the vectors. Calculations were based on the correlation matrix between participants as matrix of association. This correlation matrix was obtained using the Kendall rank correlation coefficient (Zabala, 2014). A combination of approaches (i.e. Kaiser-Guttman criterion, Humphrey's Rule of Extraction, factor eigenvalues) led us to the extraction of 4 factors and the detailed description of 3 discourses based on the first 3 factors. Because of the large overlap between discourses, we followed the most restrictive and manageable recommendation resulting from these approaches. Only 3 factors had the minimum of 2-3 significantly loading participants (at $\mathrm{p}<0,001$ level, threshold value $=3,30 * 1 / \mathrm{V}$ (number of statements) $=0,47$, Brown, 1980), necessary to confidently describe the discourses represented by those factors (Watts and Stenner, 2012)..

We manually excluded participants (i.e. excluded participants are not used as a base for the z-scores calculations) when participants had relatively low commonalities (a measure of how much a participant's sort holds in common with all other sorts; Watts and Stenner, 2012) on the first 4 factors and loaded significantly on separate factors above 4 when we intentionally extracted more factors than we expected to keep. This applied to participant (P) 4, 21, P27 and P37. Orthogonal 'Varimax' rotation was used to mathematically maximize the ratio of between over within group variation.

\subsubsection{Discourse interpretation}

The description of the discourses was based on interpretation of numerical z-scores of the statements and the qualitative post-sorting interviews (van Exel and de Graaf, 2005). To simplify quick interpretation of the decimal z-scores, we categorized them into the original sorting ranks, based on the new range delimited by the highest and lowest z-score (Table 4). Statements and interview elements were categorized based the following themes: motivation (not) to conserve mangroves, the prioritization between land-uses and between mangroves and the responsibilities of stakeholders within mangrove conservation. We distinguished between the overlapping values and

\footnotetext{
${ }^{1}$ Higher participant loadings correspond to a higher weight given to the respective participants in the calculation of the z-scores of the individual statements per factor.
}

Table 4

Categorization of the z-scores into the associated sorting ranks, based on the range delimited by the highest and the lowest z-score.

\begin{tabular}{ll}
\hline Associated rank & Z-score \\
\hline 4 & 0.981 to 1.261 \\
3 & 0.701 to 0.980 \\
2 & 0.420 to 0.700 \\
1 & 0.140 to 0.419 \\
0 & -0.281 to 0.139 \\
-1 & -0.845 to -0.282 \\
-2 & -1.409 to -0.846 \\
-3 & -1.972 to -1.410 \\
-4 & -2.537 to -1.973 \\
\hline
\end{tabular}

perspectives (no significant difference between statement z-scores), the differences in emphasis (significant difference between statement $\mathrm{z}$ scores but same category: agree or disagree) and the differences in opinion between discourses (significant difference between statement zscores and different category: agree versus disagree).

\section{Results}

\subsection{Areas of disagreement between discourses}

We can identify and describe three discourses based on the first 3 rotated factors, which explain $48.52 \%$ of the total variance (Table 2). Each factor has a different collection of significantly loading (i.e. likeminded) participants, thus each discourse is defined by the sorts of a different group of like-minded participants (Table 2). A 'discourse' consists of both the area of consensus between all participants as well as the area of disagreement that characterises that respective discourse. Due to the large overlap between discourses (with correlation ranging from 0.82 to 0.88 between factor z-scores), the described discourses on mangrove conservation and management could also be interpreted as variations of the same discourse (Fig. 1, Table 5). However, to be consistent with the $\mathrm{Q}$ methodology terminology, we refer to these variations as 'discourses'.

The following descriptions represent the areas of disagreement, characterising the three respective discourses and thus characterizing the values and perspective of participants supporting the respective discourses. They are based on the statements with significantly different statement z-scores (i.e. the weighted average of the statement rankings given by grouped participant, Table 3 ) and the post-sorting interviews.

Discourse 1 - Engaged and actively involved citizens are the key to more successful mangrove conservation and management.

Motivation - D1 generally reflects a more optimistic view regarding mangroves' usage value as an incentive for their conservation in Singapore (S36, S28, S30, S23). All cultural and regulatory ecosystem services provided by mangroves are considered relevant in Singapore and are relevant incentives for Singapore citizens to conserve mangroves.

Prioritization - Even in mangrove areas where wildlife needs are of the greatest importance, there should still be activities linked to cultural ecosystem services because these increase public advocacy for mangrove conservation. Although D1 supporters agree that disturbances to natural areas from cultural activities should be minimized (S37) the more restrictive formulation of S5 may have led to a fear of missing out on the benefits of cultural ecosystem services to mangrove conservation.

Responsibility - D1 reflect a generally less critical view of the government and its current top-down approach to mangrove conservation and management in Singapore (S12, S50, S35, S3, S24). Both the bottom-up (led by civilian or private interest groups) and the top-down (led by the government) approach to mangrove conservation and 


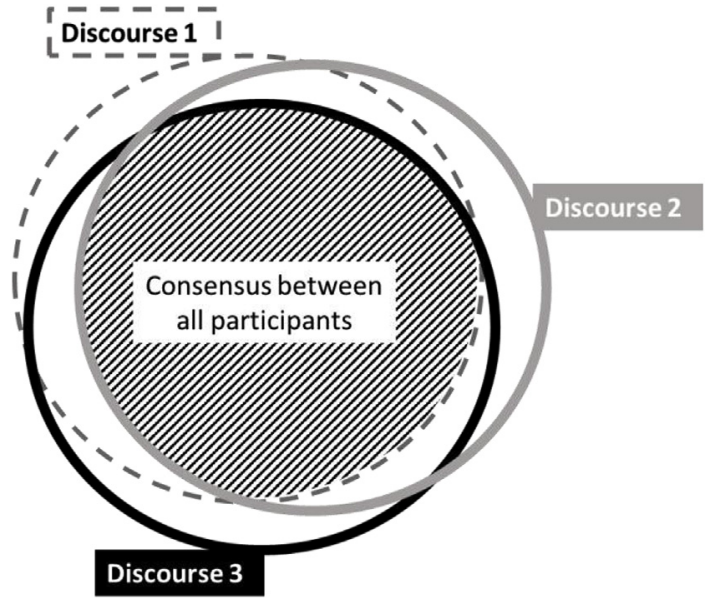

Fig. 1. Visual depiction of the structure of the three described discourses. The shaded area in the centre represents the large area of agreement or consensus between the participants (i.e. the large overlap between the identified discourses).

Table 5

Factor correlation (column 2 to 4), percentage of variance explained by the respective factors (column 5) and number of Q sorts loading significantly on the respective factors $(\mathrm{p}<0.001)$ (column 6).

\begin{tabular}{llllll}
\hline & Factor 1 & Factor 2 & Factor 3 & $\begin{array}{l}\text { Variance } \\
\text { explained (\%) }\end{array}$ & $\begin{array}{l}\text { Number of } \\
\text { loading Q sorts }\end{array}$ \\
\hline Factor 1 & 1.0 & 0.85 & 0.88 & 19.82 & 13 \\
Factor 2 & & 1.0 & 0.82 & 18.74 & 13 \\
Factor 3 & & & 1.0 & 9.96 & 4 \\
\hline
\end{tabular}

management should be equally important. Citizens can take on more responsibility, including monitoring and maintenance, under proper guidance (S15, S47, S49). However, D1 supporters remain cautious regarding public access to Environmental Impact Assessments (S50). This is due to their concern with the sensitive and/or private information contained in the EIAs which should not be shared with the larger public, such as the location of sensitive fauna and flora.

Discourse 2 - Approaches should be tailored to the unique context of Singapore to reverse currently still inadequate mangrove conservation and management.

Motivation - D2 generally reflects a more pessimistic view regarding mangroves' usage value as an incentive for their conservation in Singapore (S36, S28, S30, S23). Some mangrove uses do not apply to Singapore's unique context and should not be emphasized when motivating their conservation, e.g. mangrove's heritage value (i.e. one of the cultural uses) and the regulatory use of mangroves for climate change mitigation. D2 supporters state that most Singaporeans do not know mangroves are part of their cultural heritage. As a result, emphasizing the value of mangroves' cultural heritage is not relevant to mangrove conservation in Singapore (S28).

Prioritization - D2 reflects a generally more critical view of the government and its current top-down approach to mangrove conservation and management in Singapore (S12, S50, S35, S3, S24). The priorities of coastal and other relevant government authorities are still far from balanced, with an absolute prioritization of economic development and gain over everything else, including mangrove conservation.

Responsibility - D2 supporters are more cautious regarding the risk of actively involving citizens (including army staff) in mangrove conservation without proper (professional) guidance. They would rather encourage less intrusive ways for citizens to take more responsibility, e.g. by making environmentally conscious decisions regarding consumption and behaviour on a daily basis (S15, S47, S49). The relevant government institutions should continue to be the more important decision-makers and active mangrove managers. They still need to step up to their responsibilities.

Discourse 3 - Coastal developments and industries can have a significant positive impact on mangroves, however, the government should remain the main decision-maker and active mangrove manager.

Motivation - Prioritizing mangroves within coastal development and industries will lead to substantial benefits for both mangrove conservation and for development (S33, S17, S46). D3 supporters expect a positive effect on the public perception of private companies and government institutions, linked to the consideration of biodiversity in their actions. This, in turn, can lead to economic gains through increased investments as well as mangrove ecosystem services.

Prioritization - Developers and industrial companies can and should prioritize mangroves by funding conservation and restoration projects or by adapting coastal infrastructure to promote the re-establishment of mangrove biodiversity. Although D3 does not consider adapted coastal infrastructures to be a substitute for natural mangrove forests, it should always be encouraged where applicable since their compensation for the mangrove loss can be substantial.

Responsibility - Government institutions should continue to be the more important decision-makers and active mangrove managers. D3 supporters are generally neutral regarding the bottom-up role of different stakeholder groups (i.e. citizens, NGOs, army) in the conservation of mangrove forests, suggesting a stronger reliance on the government to conserve mangrove biodiversity relative to D1 and D2 (S15, S16, S14, S47). Citizens should be involved, only in a non-intrusive way (matching the opinion of D2 supporters) (S15, S47, S49).

\subsection{Areas of agreement between discourses}

The following descriptions represent the areas of agreement between discourses (i.e. consensus values and perspectives) (summary in Fig. 2). They are based on the statements' z-scores (Table 3) and on the post-sorting interviews. Generally, all participants agree no further loss of existing Singapore mangroves should be allowed (S2, S7, S18, S20, S37).

Motivation - Participants agree that cultural ecosystem services and especially the recreational value of mangroves should be further promoted to awaken citizen engagement towards mangrove conservation (S11, S19, S28, S30, S36, S42). Mangroves are part of Singapore's cultural heritage (e.g. the historical kampongs and Singapore's natural heritage (S28), they increase the visitation quality of Singapore's manmade and natural green areas (e.g. aesthetical value) (S30) and provide recreational (e.g. fishing, S42) as well as educational (S11) and scientific opportunities (S19). Although ranked rather neutrally, the post-sorting interviews clarify that participants agree mangroves should be visited for educational and recreational purposes (S11). The weak ranking of S11 is because participants consider unfacilitated mangroves to be unsafe (e.g. areas without boardwalks and information panels). To allow more human-nature encounters, the number of facilitated mangrove areas should be increased (S11, S16). Eco-tourism should not necessarily be promoted to compensate management costs, although there is no strong opposition against it either (S 29). Beside the importance of cultural ecosystem services, the participants themselves are personally strongly motivated by mangrove's inherent value (non-use values) to conserve mangroves (S6, S27).

Prioritization - Urban/economic development, cultural ecosystem services as well as mangrove conservation can be ensured, provided there is more efficient land-use planning. Due to the current focus on economic development in Singapore, ensuring mangrove conservation necessitates indefinite legal protection of mangroves under national park and nature reserve status (S12, S18) as well as increasing the number of areas under national park and nature reserve status (S12, S2). Continued economic development can be ensured by promoting intensification of existing industrial sites and promoting redevelopment 


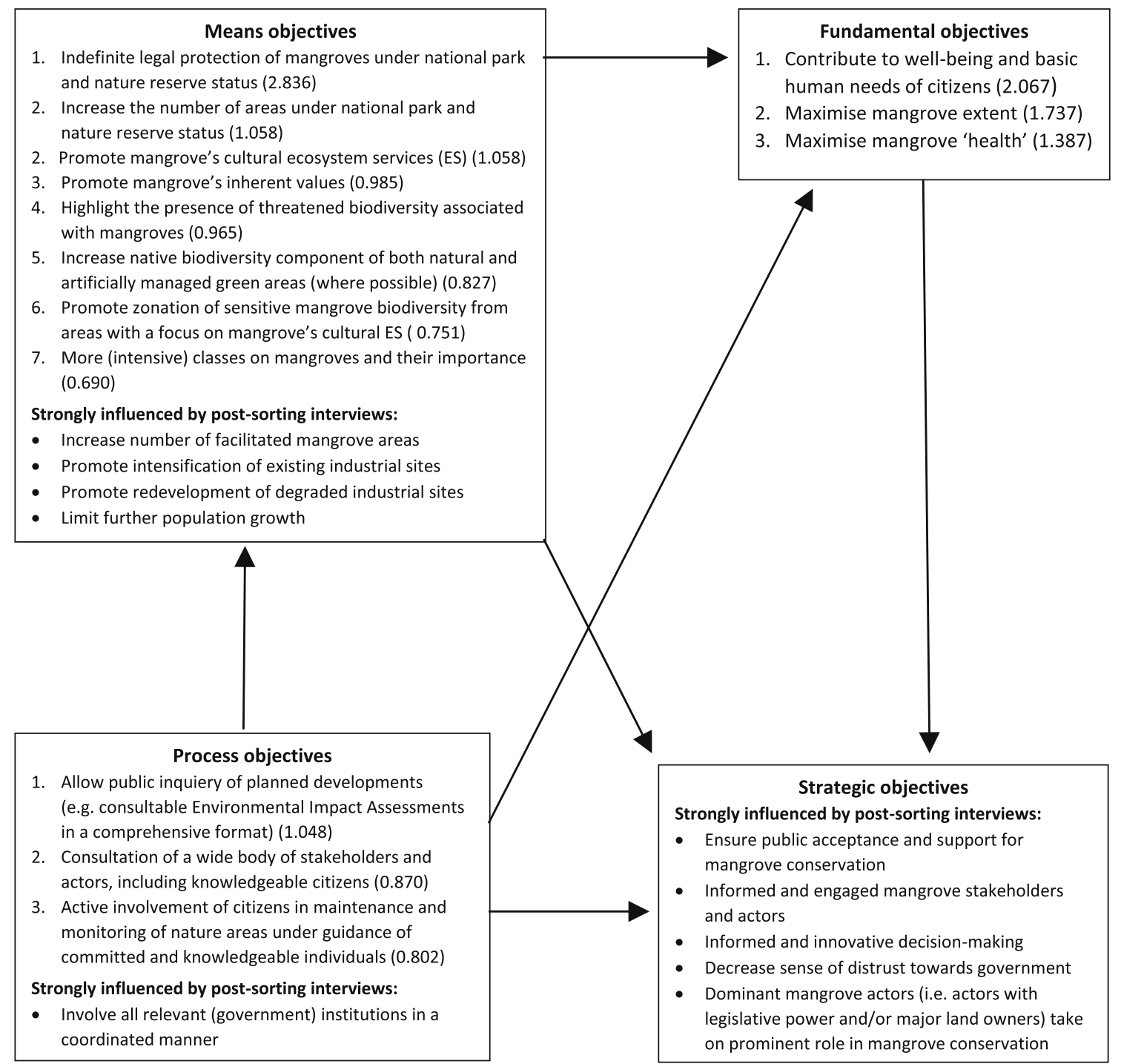

Fig. 2. 'Means-ends objective network' (Keeney, 2005; Marttunen et al., 2017) of stakeholder objectives deduced from the consensus between identified discourses (§ 3.2), based on both statement z-scores and post-sorting interviews. Objectives that are literally reflected in specific statements are ordered from highest absolute zscore (averaged over the 3 discourses) to lowest absolute z-score (averaged over the 3 discourses). When formulation was strongly influenced by post-sorting interviews, objectives could not be numerically ordered based on z-scores. Arrows indicate the direction of influence between the objectives.

of degraded industrial sites rather than reclaiming mangrove areas (S18, S39). However, further population growth should be limited to make sure economic development and mangrove conservation can coexist (S39). To limit the disturbance from recreational and educational activities to sensitive mangrove areas, mangrove areas should be subdivided in areas with a focus on sensitive mangrove biodiversity and areas with a focus on mangrove's cultural ecosystem services (S32, S37).

When it comes to prioritizing the conservation of certain mangrove areas over others, participants agree that all remaining mangrove areas should be conserved regardless of their characteristics (S2). The presence of threatened species is the only characteristic ranked systematically high by all discourses (S13), indicating it is an important incentive to increase conservation efforts (S10, S13, S31, S45). Based on the post sorting interviews, all discourses agree ecologically valuable mangrove forests should be conserved (S31). However, D3 disagrees with the implication of S31 that some areas are not ecologically valuable, which results in its neutral ranking.

Responsibility - Top-down mangrove conservation and management should be integrated into the all relevant government institutions in a coordinated way (S12). There is disagreement on the relative impact and thus importance of bottom-up initiatives compared to top-down initiatives on mangrove conservation (S15, S16, S14, S47). However, participants agree citizens should be involved in the maintenance and monitoring of nature areas, provided it is done under guidance of experienced individuals (S15, S49). Moreover, public inquiry of planned developments should be allowed (S50) and the government should consult a wide body of stakeholders and actors, including knowledgeable citizens (S34, S40, S50).

\section{Discussion}

By delineating and describing discourses on (effective) mangrove conservation and management we gain insight into their complexity (Brown et al., 2014). The shared values and perspectives - included in areas of consensus between the identified discourses - can then be used as a basis to determine shared stakeholder objectives, which are relevant in a decision-making context (Fig. 2, § 3.2, § 4.1, § 4.4) (Keeney, 2005). Because of the large overlap found between discourses, we can interpret the differences between the three discourses to be three distinct variations of one dominant discourse, characterised mainly by differences in emphasis rather than strong contradictions ( $\S 3.1$, § 4.2). 


\section{1. (Mis-)matches of consensus between discourses with current management approach in Singapore}

\subsubsection{Motivation to conserve mangroves}

To increase advocacy for mangrove conservation and management, the general (though not universal) consensus was that mangrove cultural ecosystem services (particularly recreational value) should be promoted to citizens, rather than potential economic value of mangroves in the form of provisioning services. In a highly economically developed state with limited available space, small remaining mangrove patches and a $100 \%$ urban population, people's interactions with the environment is primarily through recreational activities (Neo, 2007; Han, 2017), rather than the extraction of provisioning services such as fuelwood or (shell)fisheries. This was not always the case, Singaporeans historically had a stronger and more direct relationship with mangrove forests, with indigenous communities such as the Orang Seletar and Orang Biduanada Kallang communities living inside the mangroves and extracting provisioning services prior to British colonisation in 1819 (Murphy and Sigurdsson, 1990). However, as mangroves were lost to development and extraction of provisioning services was lost through legislation, perceptions and interactions with the environment changed, such that in the present-day Singaporeans now more strongly value tangible cultural ecosystem services such as recreation (Thiagarajah et al., 2015).

Now, the recreational value of nature and its beneficial effect on urban liveability and well-being is strongly recognised by the Singapore government and has been a main driver for its past and current conservation efforts. Moreover, the potential economic gain linked to attracting investors by creating an attractive urban environment has generated strong political will for urban greening (Lye, 2008; Henderson, 2013). The "City in a Garden" view has thus been guiding Singapore's program of intensive urban greening since its independence in 1965 and is now an important pillar of national identity (Tan, 2006; Tan et al., 2013). Such a focus on urban liveability will also have shaped stakeholder perceptions to consider mangrove management with a similar focus.

\subsubsection{Prioritization within green areas and between land uses}

The broad definition of what constitutes nature by the Singapore Government and its focus on a 'clean and green' environment has often led to the recognition of presumed aesthetically pleasing, entertaining but predominantly artificially managed areas with many non-native species as valuable green areas (Kong and Yeoh, 1996; Neo, 2007; Lye, 2008; Henderson, 2013). Whereas the identified discourses reflect a desire for a larger native biodiversity component, which is considered to render green areas more valuable to visitors. This would entail a focus on Singapore's remaining natural landscapes (such as mangrove forests) as well as the expansion of native biodiversity (including mangrove forest species) into artificially managed areas where possible. However, discourses reflect the notion that a focus on native biodiversity should not mean neglecting the comfort and safety aspects of publicly accessible natural areas, as these are aspects that are highly valued by Singapore citizens (Yuen et al., 1999). This is currently a high priority within the management of parks and nature reserves, with the quick reaction to a recent crocodile sighting on a visitor path in Sungei Buloh Wetland Reserve by increasing warning signs and extending barricades along the path a recent example of this (URL 1).

The limited land area available in Singapore has led to an extensively planned and regularly updated vision for Singapore's future. Despite the aim of creating a liveable city reflected in the 'City in a Garden' vision for Singapore, as a developmental state, economic growth remains the government's top priority within Singapore's development vision (Neo, 2007; Han, 2017). According to the identified discourses, this development vision should always prioritize redevelopment ('brownfield development') and intensification over expansion into remaining natural areas ('greenfield development'). This would allow the more efficient use of existing developed areas and allow the sparing of existing natural areas. It would also decrease the need to de-gazette existing natural areas, including parks and nature reserves, for future development purposes. This has previously occurred with mangrove nature reserves such as the Pandan Forest Reserve, which was developed in the 1960s for industrial land, and required amendments to the existing Nature Reserve Ordinance (e.g., Corlett, 1988).

\subsubsection{Responsibility of dominant stakeholders}

The characterizing top-down governance with limited and highly selective consultation towards the public within this developmental state may explain the request for increased consultation of mangrove management stakeholders in future decision-making on mangrove management. Although consultation of the public had increased after the historically weak re-election of the leading People's Action Party in 2011 (Henderson, 2013), this has apparently not been noticed by many relevant stakeholders. This relatively new and clearly welcomed increase in public consultation by government agencies may thus benefit from a more publicized approach. Improved decision-making on mangrove conservation and management also needs involvement of all relevant government institutions in a more coordinated manner. Some of the institutions with potential impact on this intertidal habitat and its components (fauna and flora) do not clearly consider this in their responsibilities (Lye, 2008).

\subsection{Disagreement between identified discourses}

Discourse 1 is characterised by a stronger emphasis on the relative importance of bottom-up approaches (compared to discourse 2 and 3) as well as a less critical stance on recent approaches of the government towards mangrove conservation and management in Singapore (compared to discourse 2).

By characterizing participants based on their personal interests and professional profile, discourse 1 seems to be mainly shaped by stakeholders with a specific interest in mangroves (rather than nature conservation in general or other ecosystems) (Table 2). This specific interest may result in discourse 1 supporters being more aware of recent changes in the government's approach to mangrove conservation and management, while supporters of discourse 2 and 3 may base their perspectives solely on their knowledge of Singapore as a developmental state throughout history. Such stakeholders often had a less critical stance towards top-down management decisions and actors, suggesting that transparency and consultation in decision-making is allied with more positive perceptions of managers. Interestingly, while stakeholders supporting discourse 1 had increased knowledge of publicgovernment consultation around mangrove management, this lead to a desire for further consultation and more bottom-up management approaches.

Discourse 2 supporters were generally quite sceptical about the promotion of certain ecosystem services - such as their value as cultural heritage sites, and particularly as carbon sinks - to generate support for mangrove conservation. This is in contradiction to recent moves at national and international policy levels to use ecosystem services such as carbon to incentivize mangrove conservation (Ullman et al., 2013; Howard et al., 2017). Similar to most countries, Singapore has made important commitments towards the reduction of Greenhouse Gas Emissions (including carbon emissions) after signing the Paris Agreement in 2015 (URL 2). Although mangroves are not explicitly mentioned within the national carbon emission reduction approach, they are explicitly mentioned within the climate change and sea level rise adaptation approach. However, Singapore's mangroves do have the ability to contribution to national carbon mitigation strategies, as they store more than 1.6 million tonnes of $\mathrm{CO}_{2}$-e, equivalent to $3.7 \%$ of national annual $\mathrm{CO}_{2}$ emissions (Friess et al., 2016). 


\subsection{Large consensus found between discourses on mangrove conservation and management}

Though three conservation discourses were identified within the stakeholder group, we found a large area of consensus, with 21 statements out of 50 statements ranked similarly by participants of all discourses (i.e. no significant differences between statement z-scores, Table 3). This suggests that disagreement between various mangrove conservation and management stakeholders may not be a prominent inhibitor of future decision making at the national scale. A comparable study by Hugé et al. (2016) - identifying stakeholder discourses on mangrove conservation and management in a rural setting of Malaysia - also observed a large overlap between discourses with correlation ranging from 0.45 to 0.50 between factor $\mathrm{z}$-scores. This may be explained by the century long implementation of the current management approach in this rural setting of the Matang Mangrove Forest Reserve (MMFR), possibly resulting in less conflicting views challenging the management (Hugé et al., 2016). However, the overlap between discourses was not as substantial as in Singapore (Table 5). It seems stakeholders realise the urban context of Singapore strongly limits the range of realistic conservation and management approaches of mangrove forests $(\S 3.2, \S 4.1$ ), resulting in the larger overlap between discourses. This is further exemplified by the wish for diversification of mangrove uses besides the main management focussing on charcoal production in the rural context of the MMFR. This wish for diversification is absent from the discourse in the urban context of Singapore, where the sole direct use of mangroves agreed with, is in the form of cultural ecosystem services.

The relatively large consensus we find does not match the pattern of strong differences between conservation discourses described in literature focussing on a larger spatial scale and biodiversity conservation in general (e.g. Martinelli, 2008; Mace, 2014; Kueffer and KaiserBunbury, 2014). However, elements from different sides of the latter 'classic conservation debate' can be recognised in the consensus values and viewpoints of conservation stakeholders in Singapore (Fig. 2). For example, all participants strongly agree that the inherent value of mangroves is an important personal motivation for mangrove conservation. However, at the same time participants recognise the importance of highlighting mangroves' cultural ecosystem services (a human-centred perspective) to motivate Singapore citizens to support mangrove conservation. This exemplifies how values and perspectives on opposite sides of the 'classic conservation debate' are complementary in practice rather than mutually exclusive (Miller et al., 2011; Robinson, 2011; Petriello and Wallen, 2015).

\subsection{Relevance to decision-makers}

In the case of complex decision-making challenges such as biodiversity conservation and management decisions, decision-makers are increasingly expected to consider multiple stakeholders and their respective objectives. The identified discourses can be used as a foundation to formulate shared objectives of multiple mangrove conservation and management stakeholders in an urban context (Fig. 2). The crucial step of identifying shared stakeholder objectives can be facilitated by structuring the consensus between identified discourses into a 'meansends objective network'. A means-ends objective network in a problem structuring method that allows a clear distinction of fundamental objectives from means objectives (i.e. how to reach the fundamental objectives), process objectives (i.e. how to approach the decision-making process itself) and strategic objectives (i.e. objectives influenced by all the decisions made over time) (Keeney, 2005; Marttunen et al., 2017). We based ourselves on the consensus values and perspectives between discourses to deduce shared objectives. These are directly applicable in a decision-making process on mangrove conservation and management in an urban context. Considering too many objectives greatly increases the complexity of the decision-making (Ishizaka and Nemery, 2013). By clearly identifying the objectives of stakeholders they can subsequently be prioritised, rendering the decision-making process feasible in reality as well as well-informed (i.e. a well-motivated and not over-simplified selection of objectives).

\subsection{Research limitations}

To increase the chances of identifying all stakeholder discourses on mangrove conservation and management present, we targeted stakeholders of mangrove conservation and management with different professional, geographical and social backgrounds, resulting in a range of knowledge and interest levels on mangroves (Table 2) (Dryzek and Niemeyer, 2008). Due to the directional sampling (rather than random sampling) approach, we cannot draw conclusions on the dominance of the three identified discourses within Singapore based on the number of participants representing the respective discourses. This will be addressed in a follow-up study, where the numerical support base of Singapore citizens for the identified discourses and the values and viewpoints embedded within is identified based on a survey approach.

\section{Conclusions}

Biodiversity conservation is not value-free. To set up the $\mathrm{Q}$ methodology interview we extracted value statements and viewpoints from peer reviewed literature on environmental issues relevant to mangrove conservation and management in Singapore. This is the first time values and viewpoints relevant to mangrove conservation and management in a highly urbanized context were analysed in a methodologically replicable way, allowing us to identify and describe stakeholder discourses on mangrove conservation and management in urban contexts.

Identifying the plurality of conservation discourses limits the range of realistic values and viewpoints, highlights consensus and areas of disagreement and yields information that is relevant to decision makers on social acceptability of conservation and management actions. However, the elaborate description of discourses does not allow decision-makers to easily consider and integrate findings into a decisionmaking process. We demonstrated an application of how the identified discourses can inform decision-making by deducing shared stakeholder objectives based on the consensus values and viewpoints and structuring these within a 'means-ends objective network' (Fig. 2). These shared objectives can readily be incorporated in decision-making processes on mangrove conservation and management in urban contexts.

The limited extent of Singapore and the government's sense that there is consequently "no room for error" has led to an extensively planned and regularly updated vision for Singapore's future. This political will for meticulous planning may not be as prominent in other cities containing mangroves in a larger urban area. However, Singapore's approach to development is expected to be increasingly copied due to the economic successes it has brought forth (e.g. China's Tianjin Eco-city project; Lucas, 2015), especially in other Asian countries which have a tradition of top-down policy making (Han, 2017). These future developments can consider the identified objectives in the planning phase to be one step ahead of future management criticisms from environmental stakeholders and from the wider public, as well as improve the long-term management and conservation of valuable mangroves forests present in these urban settings.

\section{Acknowledgements}

Katherine Vande Velde is funded by the Belgian National Research Foundation (F.R.S.-FNRS) under the title of Aspirant (F.R.S.-FNRS Grant Number 30200841) within the laboratory for Systems Ecology and Resource Management at the Université libre de Bruxelles. The fieldwork of this research was partially funded by the PADI Foundation, a California Non-Profit Public Benefit Corporation. supportThe authors wish to thank all $Q$ participants and the master student Els Van 
Mossevelde for the help during data collection in Singapore. The authors also wish to thank NParks for providing the proper permits allowing us to conduct the research (permit number: NP/RP15-146). Sponsors had no role in the study design; in the collection, analysis and interpretation of data; in the writing of the report; and in the decision to submit the article for publication. Declaration of interests: none.

\section{Appendix A. Supplementary data}

Supplementary data to this article can be found online at https:// doi.org/10.1016/j.ocecoaman.2019.05.012.

\section{References}

Adams, W.W.M., Hutton, J., 2007. People, parks and poverty: political ecology and biodiversity conservation. Conserv. Soc. 5 (2), 147-183. https://doi.org/10.2307/ 26392879.

Arts, B., Buizer, M., 2009. Forests, discourses, institutions. A discursive-institutional analysis of global forest governance. For. Policy Econ. 11, 340-347. https://doi.org/ 10.1016/j.forpol.2008.10.004.

Branoff, B.L., 2017. Quantifying the influence of urban land use on mangrove biology and ecology: a meta-analysis. Glob. Ecol. Biogeogr. 26 (11), 1339-1356.

Brown, S.R., 1980. Political Subjectivity. Applications of Q Methodology in Political Science. Yale University Press, New Haven and London.

Brown, K., 2003. Three challenges for a real people-centered conservation. Glob. Ecol. Biogeogr. 12 (2), 89-92. http://doi.wiley.com/10.1046/j.1466-822X.2003.00327.x.

Brown, S.R., Danielson, S., van Exel, J., 2014. Overly ambitious critics and the medici effect: a reply to kampen and tamás. Qual. Quantity 49 (2), 523-537.

Chan, K.M.A., Pringle, R.M., Ranganathan, J., Boggs, C.L., Chan, Y.L., Ehrlich, P.R., Haff, P.K., Heller, N.E., Al-Khafaji, K., Macmynowski, D.P., 2007. When agendas collide: human welfare and biological conservation. Conserv. Biol. 21 (1), 59-68.

Corlett, R.T., 1988. Bukit Timah: the history and significance of a small rain-forest reserve. Environ. Conserv. 15 (1), 37-44.

Corlett, R.T., 1992. The ecological transformation of Singapore, 1819-1990. J. Biogeogr. 19 (4), 411-420. http://www.jstor.org/stable/2845569? origin = crossref.

Crane, T.A., 2010. Of models and meanings: cultural resilience in socio-ecological systems of models and meanings: cultural resilience in social - ecological systems. Ecol. Soc. 15 (4), 19. https://doi.org/10.5751/ES-03683-150419.

Dryzek, J.S., 2005. The Politics of the Earth. Oxford University Press Inc, New York.

Dryzek, J.S., Niemeyer, S., 2008. Discursive representation. Am. Pol. Sci. Rev. 102 (4), 481-493. http://www.journals.cambridge.org/abstract_S0003055408080325.

Foucault, M., 1984. De wil tot weten; geschiedenis van de sexualiteit. SUN, Nijmegen.

Friess, D.A., 2017. Singapore as a long-term case study for tropical urban ecosystem services. Urban Ecosyst. 20 (2), 277-291.

Friess, D.A., Richards, D.R., Phang, V.X.H., 2016. Mangrove forests store high densities of carbon across the tropical urban landscape of Singapore. Urban Ecosyst. 19 (2), 795-810.

Gagnon Thompson, S.C., Barton, M.A., 1994. Ecocentric and anthropocentric attitudes toward the environment. J. Environ. Psychol. 14 (2), 149-157. https://doi.org/10. 1016/S0272-4944(05)80168-9.

Grey, W., 1993. Anthropocentrism and deep ecology. Australas. J. Philos. 71 (4), 463-475. https://doi.org/10.1080/00048409312345442.

Hajer, M.A., 1995. The Politics of Environmental Discourse: Ecological Modernization and the Policy Process. Oxford University Press, Oxford.

Hamilton, S.E., Casey, D., 2016. Creation of a high spatio-temporal resolution global database of continuous mangrove forest cover for the 21st century (CGMFC-21). Glob. Ecol. Biogeogr. 25 (6), 729-738.

Han, H., 2017. Singapore, a garden city: authoritarian environmentalism in a developmental state. J. Environ. Dev. 26 (1), 3-24.

Henderson, J.C., 2013. Urban parks and green spaces in Singapore Urban parks and green spaces in Singapore. Manag. Leis. 18 (3), 213-225.

Holmes, G., Sandbrook, C., Fisher, J.A., 2017. Understanding conservationists' perspectives on the new conservation debate. Conserv. Biol. 31 (2), 353-363.

Howard, J., Sutton-Grier, A., Kleypas, J. Herr D., Landis, E., Mcleod, E., Pidgeon, E., Simpson, S., 2017. Clarifying the role of coastal and marine systems in climate mitigation. Front. Ecol. Environ. 15 (1), 42-50.

Hugé, J., Vande Velde, K., Benitez-Capistros, F., Japay, J.H., Satyanarayana, B., Nazrin Ishak, M., Quispe-Zuniga, M., Mohd Lokman, B.H., Sulong, I., Koedam, N., DahdouhGuebas, F., 2016. Mapping discourses using Q methodology in Matang mangrove forest, Malaysia. J. Environ. Manag. 183 (September), 988-997. https://doi.org/10. 1016/j.jenvman.2016.09.046.

Ishizaka, A., Nemery, P., 2013. Multi-Criteria Decision Analysis. John Wiley and Sons Ltd, Chichester, UK. http://doi.wiley.com/10.1002/9781118644898.

Keeney, R.L., 2005. Developing objectives and attributes. Advances: Decision Analysis Structure 1-45.

Kong, L., Yeoh, B.S.A., 1996. Social constructions of nature in urban Singapore. South East Asian Stud. 34 (2), 402-423.

Kopnina, H., 2016. Half the earth for people (or more)? Addressing ethical questions in conservation. Biol. Conserv. 203, 176-185. https://doi.org/10.1016/j.biocon.2016. 09.019.

Kueffer, C., Kaiser-Bunbury, C.N., 2014. Reconciling conflicting perspectives for biodiversity conservation in the Anthropocene. Front. Ecol. Environ. 12 (2), 131-137.

Lai, S., Loke, L.H.L., Hilton, M.J., Bouma, T.J., Todd, P.A., 2015. The effects of urbanisation on coastal habitats and the potential for ecological engineering: a Singapore case study. Ocean Coast Manag. 103, 78-85. https://doi.org/10.1016/j.ocecoaman. 2014.11.006.

Levine, J., Chan, K.M.A., Satterfield, T., 2015. From rational actor to efficient complexity manager: exorcising the ghost of Homo economicus with a unified synthesis of cognition research. Ecol. Econ. 114, 22-32.

Lucas, L., 2015. Singapore Seeks to Export Own Model. Financial Times.

Lye, L.H., 2008. A fine city in a garden - environmental law and governance in Singapore. Singapore J. Leg. Stud. 68-117.

Mace, G.M., 2014. Whose conservation? Science 345, 1558-1560.

Martinelli, D., 2008. Anthropocentrism as a social phenomenon: semiotic and ethical implications. Soc. Semiotic. 18 (1), 79-99. http://www.scopus.com/inward/record. url?eid=2-s2.0-57749126121 andpartnerID = tZOtx3y1.

Marttunen, M., Lienert, J., Belton, V., 2017. Structuring problems for Multi-Criteria Decision Analysis in practice: a literature review of method combinations. Eur. J. Oper. Res. 263 (1), 1-17. https://doi.org/10.1016/j.ejor.2017.04.041.

Marvier, M., 2014. New conservation is true conservation. Conserv. Biol. 28 (1), 1-3.

Miller, T.R., Minteer, B.A., Malan, L.C., 2011. The new conservation debate: the view from practical ethics. Biol. Conserv. 144 (3), 948-957. https://doi.org/10.1016/j. biocon.2010.04.001.

Miller, B., Soulé, M.E., Terborgh, J., 2014. "New conservation" or surrender to development? Anim. Conserv. 17 (6), 509-515.

Mukherjee, N., Zabala, A., Hugé, J., Ochieng, N.T., Esmail, B.A., Sutherland, W.J., 2017. Comparative anatomy of techniques for eliciting views and judgements in decisionmaking. Methods Ecol. Evol. (June), 54-63 2018.

Murphy, D.H., Sigurdsson, J.B., 1990. Birds, mangroves and man: prospects and promise of the new Sungei Buloh bird reserve. In: Chou, L.M., Ng, P.K.L. (Eds.), Essays in Zoology. Department of Zoology, National University of Singapore, pp. 233-243.

Neo, H., 2007. Challenging the developmental state: nature conservation in Singapore Asia Pac. Viewp. 48 (2), 186-199.

Neumann, B., Vafeidis, A.T., Zimmermann, J., Nicholls, R.J., 2015. Future coastal population growth and exposure to sea-level rise and coastal flooding - a global assessment. PLoS One 10 (3).

Nfotabong-Atheull, A., Din, N., Dahdouh-Guebas, F., 2013. Qualitative and quantitative characterization of mangrove vegetation structure and dynamics in a peri-urban setting of Douala (Cameroon): an approach using air-borne imagery. Estuar. Coasts 36 (6), 1181-1192.

Ostrom, E., 1999. Coping with tragedies of the commons. Annu. Rev. Pol. Sci. 2, 493-535. https://doi.org/10.1146/annurev.polisci.2.1.493.

Ostrom, E., 2009. A general framework for analyzing sustainability of social-ecological systems. Science 325 (July), 419-422.

Petriello, M.A., Wallen, K.E., 2015. Integrative reflections on the new conservation science debate. Biodivers. Conserv. 24 (6), 1549-1551.

Redman, C.L., Grove, J.M., Kuby, L.H., 2004. Integrating social science into the LongTerm Ecological Research (LTER) Network: social dimensions of ecological change and ecological dimensions of social change. Ecosystems 7 (2), 161-171. https://doi. org/10.1007/s10021-003-0215-z.

Reed, M.S., Graves, A., Dandy, N., Posthumus, H., Hubacek, K., Morris, J., Prell, C., Quinn, C.H., Stringer, L.C., 2009. Who's in and why? A typology of stakeholder analysis methods for natural resource management. J. Environ. Manag. 90 (5), 1933-1949.

Richards, D.R., Friess, D.A., 2016. Rates and drivers of mangrove deforestation in Southeast Asia, 2000-2012. Proc. Natl. Acad. Sci. Unit. States Am. 113 (2), 344-349. http://www.pnas.org/lookup/doi/10.1073/pnas.1510272113.

Richards, D.R., Friess, D.A., 2017. Characterizing coastal ecosystem service trade-offs with future urban development in a tropical city. Environ. Manag. 60, 961-973.

Robinson, J.G., 2011. Ethical pluralism, pragmatism, and sustainability in conservation practice. Biol. Conserv. 144 (3), 958-965. https://doi.org/10.1016/j.biocon.2010. 04.017.

Shufen, Y., Lim, R.F., Chiou-rong, S., Yong, J.W.H., 2012. The Current Status of Mangrove Forests in Singapore. pp. 99-120 October.

Soulé, M.E., 1985. What is conservation biology? Bioscience 35 (11), 727-734. http:// www.jstor.org/stable/10.2307/1310054.

Soulé, M.E., 2013. The "new conservation. Conserv. Biol. 27 (5), 895-897.

Stojanovic, T., McNae, H.M., Tett, P., Potts, T.W., Reis, J., Smith, H.D., Dillingham, I., 2016. The "social" aspect of social-ecological systems: a critique of analytical frameworks and findings from a multisite study of coastal sustainability. Ecol. Soc. 21 (3), 15. https://doi.org/10.5751/ES-08633-210315.

Sutherland, W.J., Pullin, A.S., Dolman, P.M., Knight, T.M., 2004. The need for evidencebased conservation. Trends Ecol. Evol. 19 (6), 305-308. http://linkinghub.elsevier. com/retrieve/pii/S0169534704000734.

Tallis, H., Lubchenco, J., 2014. A call for inclusive conservation. Nature 515, 27-28.

Tan, K.W., 2006. A greenway network for Singapore. Landsc. Urban Plan. 76, 45-66.

Tan, P.Y., Wang, J., Sia, A., 2013. Perspectives on five decades of the urban greening of Singapore. Cities 32, 24-32. https://doi.org/10.1016/j.cities.2013.02.001.

Thiagarajah, J., Wong, S.K.M., Richards, D.R., Friess, D.A., 2015. Historical and contemporary cultural ecosystem service values in the rapidly urbanizing city state of Singapore. Ambio 44, 666-677.

Thomas, N., Lucas, R., Bunting, P., Hardy, A., Rosenqvist, A., Simard, M., 2017. Distribution and drivers of global mangrove forest change, 1996-2010. PLoS One 12 (6), 1-14. https://doi.org/10.1371/journal.pone.0179302.

Ullman, R., Bilbao-Bastida, V., Grimsditch, G., 2013. Including blue carbon in climate market mechanisms. Ocean Coast Manag. 83, 15-18.

United Nations, Department of Economic and Social Affairs, Population Division, 2014. 
World Urbanization Prospects: The 2014 Revision, Highlights (ST/ESA/SER.A/352). van Exel, J., de Graaf, G., 2005. Q methodology ;: a sneak preview. Soc. Sci. 2, 1-30. http://qmethod.org/articles/vanExel.pdf Retrieved from.

Watts, S., Stenner, P., 2012. Doing Q Methodological Research. Sage Publications. Yee, A.T.K., Ang, W.F., Teo, S., Liew, S.C., Tan, H.T.W., 2010. The present extent of mangrove forests in Singapore. Nature in Singapore 3 (June), 139-145.

Yee, A.T.K., Corlett, R.T., Liew, S.C., Tan, H.T.W., 2011. The vegetation of Singapore an updated map. Gardens' Bulletin Singapore 63 (1and2), 205-212.
Yuen, B., Kong, L., Briffett, C., 1999. Nature and the Singapore resident. Geojournal 49 (3), 323-331.

Zabala, A., 2014. qmethod: a package to explore human perspectives using Q methodology. The R Journal 6 (2), 163-173.

Zabala, A., Sandbrook, C., Mukherjee, N., 2018. When and how to use Q methodology to understand perspectives in conservation research. Conserv. Biol. 32 (5), 1185-1194. https://doi.org/10.1111/cobi.13123. 